\title{
Use of Eculizumab in Thrombotic Microangiopathy Associated with Hematopoietic Stem Cell Transplantation
}

\author{
Sinan Demircioglu ${ }^{1}$, Ali Dogan ${ }^{2}$ and Cengiz Demir ${ }^{2}$ \\ ${ }^{1}$ Department of Hematology, Meram Faculty of Medicine, Necmettin Erbakan University, Konya, Turkey \\ ${ }^{2}$ Department of Hematology, Faculty of Medicine, Van Yuzuncu Yll University, Van, Turkey
}

\begin{abstract}
Thrombotic microangiopathy (TMA) associated with hematopoietic stem cell transplantation, remains a difficult complication due to its high mortality rate, lack of standardised diagnostic criteria, and limited treatment options. Although the etiology of the disease is not clear, medications, radiotherapy, graft-versus-host disease (GVHD), angioinvasive fungal, viral infections and complement activation have been implicated. Agents such as therapeutic plasma exchange (TPE), steroids, rituximab, defibrotide, eculizumab are used in its treatment. The use of treatments such as TPE, steroids, defibrotide, and rituximab did not yield satisfactory results in transplant-associated TMA (TA-TMA). Recent studies have reported successful results with eculizumab in the treatment of TA-TMA. As there is no standard dose for eculizumab in the treatment of TA-TMA, doses used in atypical hemolytic uremic syndrome (aHUS) were administered. In this paper, we present a case that was unresponsive to TPE and steroids, but which was successfully treated with eculizumab.
\end{abstract}

Key Words: Acute myeloid leukemia, Stem cell transplantation, Thrombotic microangiopathy, Apheresis, Eculizumab.

How to cite this article: Demircioglu S, Dogan A, Demir C. Use of Eculizumab in Thrombotic Microangiopathy Associated with Hematopoietic Stem Cell Transplantation. J Coll Physicians Surg Pak 2021; 31(11):1359-1361.

\section{INTRODUCTION}

Transplant-associated thrombotic microangiopathy (TA-TMA) is an endothelial damage syndrome that is seen as a complication of both autologous and allogenic hematopoietic stem cell transplantation (HSCT). It is a disease with high mortality, which is frequently seen in the first 100 days. ${ }^{1}$ Although the etiology of the disease is not clear, medications (cyclosporine, high dose chemotherapy, sirolimus, etc.), radiotherapy, graft-versus-host disease (GVHD), angioinvasive fungal or viral infections have been implicated. Complement mutations and uncontrolled complement activation are also included in the etiology of the disease. ${ }^{2}$ TA-TMA is characterised by thrombocytopenia, anemia, the presence of schistocytes in peripheral blood smear, and renal and neurological findings. Its diagnosis can be difficult due to overlap of its clinical symptoms with other common complications, including GVHD and infections. ${ }^{3}$ For diaognosis of TA-TMA, schistocytes $>4 \%$ in peripheral smear, thrombocytopenia of $<50 \times 10^{9} / \mathrm{L}$ or $>50 \%$ reduction compared to the previous count of platelets, increased serum lactate dehydrogenase (LDH), decrease in hemoglobin concentration, and serum haptoglobin reduction are required. ${ }^{4}$

Correspondence to: Dr. Sinan Demircioglu, Department of Hematology, Meram Faculty of Medicine, Necmettin

Erbakan University, Turkey

E-mail: sinandemircioglumd@gmail.com

Received: December 04, 2019; Revised: February 21, 2020;

Accepted: March 09, 2020

DOI: https://doi.org/10.29271/jcpsp.2021.11.1359

\section{CASE REPORT}

A 46-year female patient was diagnosed with acute myeloid leukemia (AML) in July 2017. One cycle of remission induction chemotherapy and four cycles of consolidation chemotherapy were administered to the patient and she was followed up without administration of any medication. The disease recurred in September 2018, 9 months after the administration of the last chemotherapy cycle. In October 2018, allogeneic stem cell transplantation was performed to the patient, whose condition was in remission after recovery from chemotherapy, from her brother, a fully compatible donor. On the $155^{\text {th }}$ day of the transplantation, the patient developed gastrointestinal GVHD. Her GVHD was successfully treated with methyl prednisolone and cyclosporine. Methyl prednisolone and cyclosporine were discontinued on $180^{\text {th }}$ day. The patient presented with fatigue on the $195^{\text {th }}$ day, whose tests revealed the following results: 8.3 $\mathrm{g} / \mathrm{dl}$ of hemoglobin, $4,420 / \mu \mathrm{L}$ leukocyte count, $29,000 / \mu \mathrm{L}$ platelet count, $0.8 \mathrm{mg} / \mathrm{dl}$ of creatinine, $57 \mathrm{U} / \mathrm{LAST}, 94 \mathrm{U} / \mathrm{L} \mathrm{ALT}, 6$ $\mathrm{mg} / \mathrm{L}$ of CRP, $1072 \mathrm{U} / \mathrm{LLDH}, 175 \mathrm{U} / \mathrm{L} \mathrm{GGT}, 172 \mathrm{U} / \mathrm{LALP}, 1.8 \mathrm{mg} / \mathrm{dl}$ of indirect bilirubin, INR 1.1, PT $12 \mathrm{sec}$, APTT $30 \mathrm{sec}, 328 \mathrm{mg} / \mathrm{dl}$ of fibrinogen, and $0.4 \mu \mathrm{g} / \mathrm{ml}$ of D-Dimer. Schistocytes, spherocytes, polychromasia and thrombocytopenia were traced in peripheral smear (PS) (Figure 1). ADAMTS 13 enzyme level was detected as $1 \mathrm{IU} / \mathrm{ml}(0.40-0.30)$. No paroxysmal nocturnal hemoglobinuria (PNH) clone was detected. Bonemarrow examination revealed the disease to be in remission. The patient was thought to have TA-TMA and thus treatment with $1 \mathrm{mg} / \mathrm{kg}$ methyl prednisolone and plasmapheresis was commenced. It was decided to start eculizumab treatment to the patient who 
did not respond to therapeutic plasma exchange (TPE) and methyl prednisolone treatment, which was given for two weeks. Eculizumab was administered at a dose of $900 \mathrm{mg}$ once a week for the first four weeks and then 1200 mg every two weeks. Following the second dose of eculizumab, the patient exhibited clinical improvement, which was also reflected in her laboratory results. After the administration of the sixth dose of eculizumab, hemoglobin increased to $12.2 \mathrm{~g} / \mathrm{dl}$ and platelet count increased to $154,000 / \mu \mathrm{L}$, whereas $\mathrm{LDH}$ decreased to $205 \mathrm{U} / \mathrm{L}$ and indirect bilirubin decreased to $0.8 \mathrm{mg} / \mathrm{dl}$. Schistocytes disappeared in PS. Eculizumab was administered for three months and then discontinued. It has been five months since eculizumab was discontinued, and TA-TMA has not yet recurred.

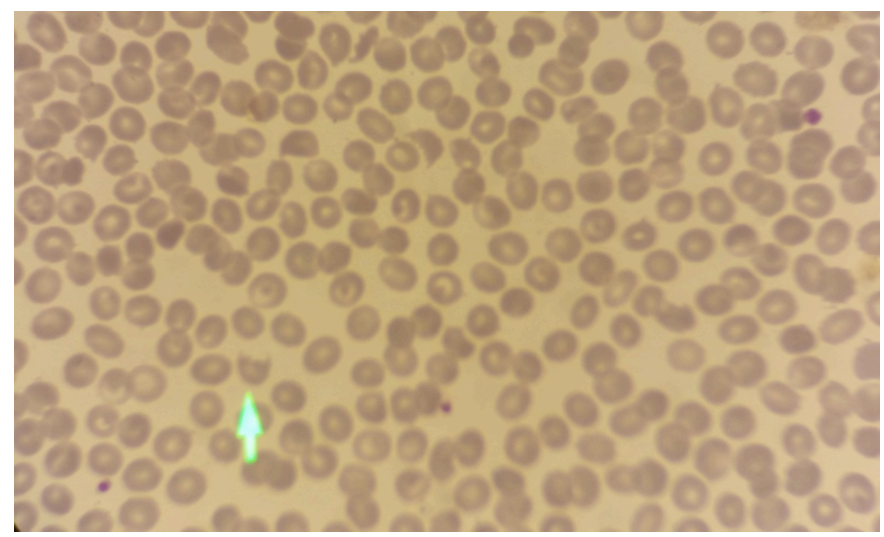

Figure 1: Schistocytes (arrow), spherocytes, polychromasia and thrombocytopenia were found in peripheral smear.

\section{DISCUSSION}

The first-line treatment of TA-TMA is limited to the discontinuation or reduction of the medication causing the endothelial damage, and the supportive treatment, including the treatment of the infections, that may aggravate TMA and aggressive hypertension, and of the common conditions such as GVHD. ${ }^{5}$ TPE, which is the main therapeutic approach for thrombotic thrombocytopenic purpura (TTP), is not useful in TA-TMA. Various studies conducted over the past 15 years have shown that the results of administering TPE in the treatment of TTP are highly variable. In these studies, the response rates to TPE ranged from $27 \%$ to $80 \%$, whereas the mortality rates ranged from $44 \%$ to $100 \% .^{5,6}$ There are many factors that affect the efficacy of TPE, such as timing of the procedure, presence of accompanying acute GVHD, antibodies such as anti-Factor $\mathrm{H}$, and presence of donor or recipient-specific antibodies. ${ }^{7,8}$ However, early initiation of TPE treatment may be useful in some patients modifying dysfunctional complement regulators, and removing anti-Factor $\mathrm{H}$ antibodies or inflammatory cytokines, and endothelial injury promoters such as circulating endothelial cells, endothelial microparticles, and circulating free hemoglobin. 5,9

The classical and more recently, the alternative complement pathway is thought to be primarily responsible for the pathophysiology of TA-TMA. Taking this into consideration, terminal complement inhibitors such as eculizumab, a C5 inhibitor, have emerged as a promising new agents in these patients. ${ }^{10}$
Recently, some case reports and small scale studies have reported the successful use of eculizumab in TA-TMA. In these studies and case reports, $67-92 \%$ of patients showed improvement. ${ }^{11-13}$ As there is no standard dose for eculizumab used in the treatment of TA-TMA, doses used in atypical hemolytic uremic syndrome (aHUS) were administered. ${ }^{12}$ Compared to aHUS, administration of eculizumab in TA-TMA typically requires a longer induction time with at least 4-6 weeks of treatment. In addition, unlike aHUS, eculizumab may be discontinued after the patient has recovered from TMA and lifelong treatment is not required. ${ }^{10}$ In our case, patient did not respond to steroids and TPE, but she responded dramatically to eculizimab treatment. The patient began to recover after the administration of second dose. The treatment was discontinued after three months and the disease has still not recurred.

In the presence of signs of post-transplant microangiopathic hemolytic anemia, TA-TMA should be considered among the preliminary diagnoses. Medications such as cyclosporine and tacrilumus should be discontinued or their doses should be reduced. Since the response rates to TPE and steroids are low, eculizumab treatment should be started immediately in unresponsive patients.

\section{PATIENT'S CONSENT:}

Informed consent was obtained from the patient.

\section{CONFLICT OF INTEREST:}

The authors declared no conflict of interest.

\section{AUTHORS' CONTRIBUTION:}

SD: Concept and manuscript writing.

AD: Data collection.

CD: Manuscript review.

\section{REFERENCES}

1. Nadir $Y$, Brenner B. Hemorrhagic and thrombotic complications in bone marrow transplant recipients. Thromb Res 2007; 120 Suppl 2: S92-8. doi: 10.1016/ S0049-3848(07)70136-6.

2. Ricklin D, Cines DB. TMA: Beware of complements. Blood 2013; 122(12):1997-9. doi: 10.1182/ blood-2013-07512707.

3. Rosenthal J. Hematopoietic cell transplantation-associated thrombotic microangiopathy: A review of pathophysiology, diagnosis, and treatment. J Blood Med 2016; 7:181-6. doi: 10.2147/JBM.S102235.

4. Ruutu T, Barosi G, Benjamin RJ, Clark RE, George JN, Gratwohl A, et al. Diagnostic criteria for hematopoietic stem cell transplant-associated microangiopathy: Results of a consensus process by an international working group. Haematologica 2007; 92(1): 95-100. doi: 10.3324/ haematol.10699.

5. Laskin BL, Goebel J, Davies SM, Jodele S. Small vessels big trouble in the kidneys and beyond: Hematopoietic stem cell transplantation-associated thrombotic microangiopathy. Blood 2011; 118(6):1452-62. doi: 10.1182/blood-201102-321315.

6. Ho VT, Cutler C, Carter S, Martin P, Adams R, Horowitz M, et 
al. Blood and marrow transplant clinical trials network toxicity committee consensus summary: Thrombotic microangiopathy after hematopoietic stem cell transplantation. Biol Blood Marrow Transplant 2005; 11(8): 571-5. doi: 10.1016/j.bbmt.2005.06.001.

7. Erdbruegger U, Woywodt A, Kirsch T, Haller H, Haubitz M. Circulating endothelial cells as a prognostic marker in thrombotic microangiopathy. Am J Kidney Dis 2006; 48(4):564-70. doi: 10.1053/j.ajkd.2006.06.013.

8. Kennedy GA, Kearey N, Bleakley S, Butler J, Mudie K, Durrant S. Transplantation-associated thrombotic microangiopathy: Effect of concomitant GVHD on efficacy of therapeutic plasma exchange. Bone Marrow Transplant 2010; 45(4):699-704. doi: 10.1038/bmt.2009.233.

9. Thachil J. The role for adjunctive treatment to plasma exchange in thrombotic thrombocytopenic purpura. Nephrol Dial Transplant 2008; 23(8):2701-2. doi: 10.1093/ndt/gfn173.
10. Khosla J, Yeh AC, Spitzer TR, Dey BR. Hematopoietic stem cell transplant-associated thrombotic microangiopathy: Current paradigm and novel therapies. Bone Marrow Transplant 2018; 53(2):129-37. doi: 10.1038/bmt.2017. 207.

11. Jodele S, Laskin BL, Dandoy CE, Yers KC, El-Bietar J, Davies $\mathrm{SM}$, et al. A new paradigm: Diagnosis and management of HSCT-associated thrombotic microangiopathy as multisystem endothelial injury. Blood Rev 2015; 29(3):191-204. doi: 10.1016/j.blre.2014.11.001.

12. Jodele S, Fukuda T, Vinks A, Mizuno K, Laskin BL, Goebel J, et al. Eculizumab therapy in children with severe hematopoietic stem cell transplantation-associated thrombotic microangiopathy. Biol Blood Marrow Transplant 2014; 20(4):518-25. doi.org/10.1016/j.bbmt.2013.12.565

13. Dhakal P, Giri S, Pathak R, Bhatt VR. Eculizumab in transplant-associated thrombotic microangiopathy. Clin Appl Thromb Hemost 2017; 23(2):175-80. doi: 10.1177/ 1076029615599439. 